\title{
Topoisomerase II alpha gene amplification is a favorable prognostic factor in patients with HER2-positive metastatic breast cancer treated with trastuzumab
}

George Fountzilas $^{1 *+}$, Christos Christodoulou ${ }^{2+}$, Mattheos Bobos ${ }^{3}$, Vassiliki Kotoula ${ }^{3,4}$, Anastasia G Eleftheraki ${ }^{5}$, Ioannis Xanthakis ${ }^{1}$, Anna Batistatou ${ }^{6}$, George Pentheroudakis ${ }^{7}$, Nikolaos Xiros ${ }^{8}$, Irene Papaspirou ${ }^{9}$, Anna Koumarianou ${ }^{8}$, Pavlos Papakostas ${ }^{10}$, Dimitrios Bafaloukos ${ }^{11}$, Dimosthenis V Skarlos ${ }^{2}$ and Konstantine T Kalogeras ${ }^{1,12}$

\begin{abstract}
Background: The vast majority of patients with HER2-positive metastatic breast cancer (MBC) treated with trastuzumab eventually develop resistance to this agent. There is an unmet need therefore, for identifying biological markers with possible prognostic/predictive value in such patients. The aim of this study was to investigate the prognostic role of topoisomerase II alpha gene (TOP2A) amplification and protein (Topolla) expression in patients treated with trastuzumab-containing regimens.

Methods: Formalin-fixed paraffin-embedded tumor tissue samples were retrospectively collected from 225 eligible patients treated with trastuzumab. Protein expression of ER, PgR, Ki67, PTEN, HER2 and Topolla were centrally assessed by immunohistochemistry. HER2 and TOP2A gene amplification was evaluated by fluorescence in situ hybridization. PIK3CA mutations were identified by single nucleotide polymorphism genotyping. Survival was evaluated from the initiation of trastuzumab as 1st line treatment to the date of last follow-up or death.

Results: Among the 225 samples analyzed, only 137 (61\%) were found to be HER2-positive. TOP2A was amplified in $41 \%$ and deleted in $16 \%$ of such tumors. TOP2A gene amplification was more frequent in ER-negative tumors. Topolla protein expression was observed in the majority (65\%) of the samples and was associated with ER-positive status, high Ki67 expression, presence of PTEN protein and PIK3CA mutations. Median follow-up for patients treated in the 1st line was 51 months. Survival was more prolonged with trastuzumab-containing treatment in HER2-positive patients (50 months, log-rank, $p=0.007$ ). TOP2A non-amplified or deleted tumors were associated with increased risk for death compared to TOP2A amplified tumors ( $H R=2.16$, Wald's $p=0.010$ and $H R=2.67, p=0.009$, respectively). In multivariate analysis, a significant interaction of TOP2A with anthracycline treatment (either in the adjuvant or the 1 st line setting) was observed for survival (Wald's $p=0.015$ ). Among the TOP2A amplified subgroup, anthracycline-treated patients were associated with decreased risk for death.

(Continued on next page)
\end{abstract}

\footnotetext{
*Correspondence: fountzil@auth.gr

${ }^{\dagger}$ Equal contributors

'Department of Medical Oncology, "Papageorgiou" Hospital, Aristotle University of Thessaloniki School of Medicine, 564 03, Thessaloniki, Macedonia, Greece

Full list of author information is available at the end of the article
} 
(Continued from previous page)

Conclusions: TOP2A gene amplification was shown to be a favorable prognostic marker in HER2-positive MBC patients treated with trastuzumab, such an effect however, appears to rather be related to treatment with anthracyclines (predictive marker for benefit from anthracyclines). The results of the present retrospective study warrant validation in larger cohorts of patients treated in the context of randomized trials.

Keywords: Breast cancer, Topoisomerase II alpha, Fluorescence in situ hybridization, Gene amplification, Trastuzumab, Prognostic factors, Anthracyclines, Predictive factors

\section{Background}

Metastatic breast cancer (MBC) is an incurable disease. Chemotherapy or hormonal therapy mainly has a palliative role, although newer agents may contribute to a significant prolongation of survival $[1,2]$. HER2, a protooncogene located on chromosome 17q21.1, is amplified in approximately $20 \%$ of breast cancers and is associated with a number of adverse prognostic factors, such as axillary node involvement, advanced stage, hormone receptor (HR)-negativity and increased proliferation indices $[3,4]$. Trastuzumab (Herceptin ${ }^{\circledR}$, Genentech, San Francisco, CA), a recombinant humanized monoclonal antibody against the HER2 protein, was found to prolong progression-free survival (PFS) and overall survival (OS) of patients with MBC and HER2 gene amplification or HER2 protein overexpression $[5,6]$.

Nevertheless, it has become evident from numerous clinical trials that a considerable number of patients with $\mathrm{MBC}$ do not benefit from the administration of trastuzumab, either as a single agent or in combination with other systemic treatments. Moreover, in almost all patients who initially respond to trastuzumab-based treatments, tumor progression is eventually expected to occur. On the other hand, it is conceivable that any given targeted treatment is cost-effective only when it is administered exclusively to those patients who will derive the greatest benefit from it, sparing all other patients from unnecessary side effects. Therefore, there is an imperative need for identifying biological markers that will predict which patients are most likely to respond to trastuzumab-based treatments.

The topoisomerase II alpha gene $(T O P 2 A)$ is located telomerically to HER2 at 17q21-q22 and encodes for topoisomerase II alpha (TopoIIa), a 170-kd cell cycle regulated protein [7]. The TOP2A gene is considered to be within the HER2 amplicon [8], although it is not included in the "smallest region of amplification" [9] and may follow a different fate than HER2 in terms of copy number alterations [10]. Topoisomerases II are considered to be targets of anthracyclines [11], while TOP $2 A$ gene amplification has been linked to anthracycline sensitivity in patients with advanced breast cancer $[12,13]$ or in patients with high-risk primary breast cancer receiving adjuvant chemotherapy [14-16] (reviewed in
[17]). On the other hand, the predictive value of TOP $2 A$ has been refuted by several retrospective studies [18-20] however, flaws in the statistical design and the methodological approaches used in these studies undermine the credibility of such opinions. In fact, a number of investigators believe that TopoIIa protein expression is more relevant than $T O P 2 A$ gene status in predicting response to anthracyclines [21].

It is noteworthy, that although extensive research efforts have been devoted to the evaluation of the potential predictive role of TOP $2 A$ gene status with respect to anthracycline responsiveness, little attention has been paid to $T O P 2 A$ gene alterations with regard to the outcome of breast cancer patients following treatment with trastuzumab in advanced stages. The main objectives of the present study were to explore the impact of TOP2A gene status and TopoIIa protein expression on the outcome of $\mathrm{MBC}$ patients treated with trastuzumabcontaining regimens and their possible interaction with anthracycline-containing treatment. The study was retrospective in nature and was performed on archival tissue material (formalin-fixed paraffin-embedded, FFPE) from our Group's Tumor Repository. In addition, based on the adverse prognostic effect of PIK3CA mutations and PTEN protein loss in the same patient cohort, as previously shown [22], we investigated the association of these parameters with TOP2A gene and protein status.

\section{Patients and methods}

The medical records of all patients with $\mathrm{MBC}$ treated with trastuzumab-based regimens, between December 1998 and January 2010, were retrospectively reviewed. Eligibility criteria for this study were a: histologically confirmed MBC; b: adequacy of clinical data on patient's history, demographics, tumor characteristics, treatment details (drug dosages, schedule of administration, serious toxicities) and clinical outcome; c: availability of adequate FFPE tumor tissue for biological marker evaluation; and $\mathrm{d}$ : trastuzumab-based treatment for metastatic disease. The translational research protocol was approved by the Bioethics Committee of the Aristotle University of Thessaloniki School of Medicine (Protocol \# 4283; Jan 14, 2008) under the general title "Investigation of major mechanisms of resistance to treatment with trastuzumab 
in patients with metastatic breast cancer". All patients included in the study after 2005 provided written informed consent for the provision of biological material for future research studies before receiving any treatment. Waiver of consent was obtained from the Bioethics Committee for patients included in the study before 2005 .

\section{Tissue Material}

FFPE tumor tissue samples were retrospectively collected from 246 breast cancer patients treated with trastuzumab-based regimens in the metastatic setting. Twenty-one cases were excluded for inadequate FFPE tumor tissue, thus decreasing the number of eligible/evaluable patients to 225. A REMARK diagram for the translational research studies is provided in Figure 1. Representative hematoxylin-eosin stained sections from the tissue blocks were reviewed by a pathologist (M.B.). The most representative tumor areas were marked for the construction of tissue microarray (TMA) blocks, as previously described [22]. Each TMA block also contained cores from various neoplastic, non-neoplastic and reactive tissues serving as assay controls. Cases not represented, damaged or inadequate on the TMA sections were re-cut from the original blocks and these sections were used for protein and gene analysis.

\section{Immunohistochemistry (IHC)}

Immunohistochemical labeling was performed according to standard protocols on serial $2.5 \mu \mathrm{m}$ thick sections from the original blocks or the TMA blocks. All cases were also stained for vimentin (clone V9, Dako,
Glostrup, Denmark) and cytokeratin 8/18 (clone 5D3, Novocastra $^{\mathrm{TM}}$, Leica Biosystems, Newcastle, U.K), which were used as control stains for tissue immunoreactivity and fixation, as well as identification of tumor cells. Tissue samples negative for the above antibodies were excluded from the study. The staining procedures for estrogen receptor (ER, clone $6 \mathrm{~F} 11$, Novocastra ${ }^{\mathrm{TM}}$, Leica Biosystems), progesterone receptor (PgR, clone 1A6, Novocastra $^{\text {TM }}$, Leica Biosystems), HER2 (A0485 polyclonal antibody, Dako) and Ki67 (clone MIB-1, Dako) were performed using a Bond $\operatorname{Max}^{\text {TM }}$ autostainer (Leica Microsystems, Wetzlar, Germany), as previously described [23]. TopolIa protein expression was evaluated using the KiS1 monoclonal antibody (Dako), as previously described [24] with slight modifications (antibody dilution: 1:200; detection system: Envision ${ }^{\mathrm{TM}}$, Dako). PTEN (phosphatase and tensin homologue deleted on chromosome 10) protein expression was evaluated using the $6 \mathrm{H} 2.1$ monoclonal antibody (Dako), as previously described [25]. The evaluation of all IHC sections was done by experienced in breast cancer pathologists (M.B. and A.B.), blinded as to the patients' clinical characteristics and survival data. To assure optimal immunoreactivity, the sections of the TMA blocks were stained in one run for each antibody, shortly after mounting of the TMA sections on positively charged glass slides.

\section{Interpretation of the IHC results}

ER and PgR, HER2, Ki67 and PTEN immunostaining was evaluated according to existing established criteria [26-29], as previously described [22]. Briefly, ER and PgR

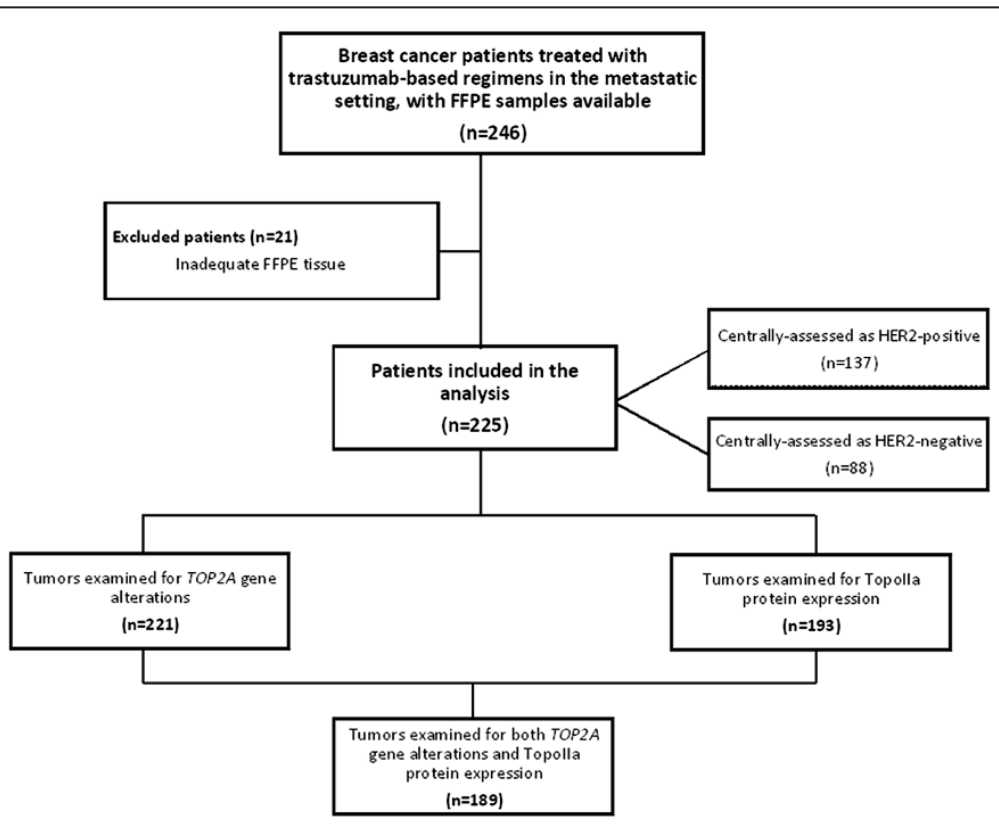

Figure 1 REMARK diagram. FFPE tissue availability in the present study for the application of different analytical techniques for the determination of HER2 and TOP2A gene amplification status and HER2 and Topolla protein expression is presented in detail. 
were evaluated using the Histoscore method (max score: 400) and were considered positive if staining was present in $\geq 1 \%$ of tumor cell nuclei [26]; HER2 protein expression was scored in a scale from 0 to $3+$, the latter corresponding to uniform, intense membrane staining in $>30 \%$ invasive tumor cells [27]; for Ki67, the expression was defined as low $(<14 \%)$ and high $(\geq 14 \%)$ based on the percentage of stained/unstained nuclei from the tumor areas [28]; and, PTEN protein expression (cytoplasmic, nuclear or both) was evaluated according to a staining intensity scale from 0 (negative, no staining) to 3 (intense staining), whereby tumors with PTEN scores of 0 or 1 were considered to have PTEN loss [29]. For Topolla immunostaining, a tumor was considered to be positive if moderate to intense nuclear staining was detected in $>5 \%$ of tumor cells [30].

\section{Fluorescence in situ hybridization (FISH)}

TMA sections or whole sections (5 $\mu$ m thick) were cut for FISH analysis, using the ZytoLight ${ }^{\circledR}$ SPEC HER2/ TOP2A/centromere 17 (CEN17) triple color probe kit (ZytoVision, Bremerhaven, Germany). FISH was performed according to the manufacturer's protocol with minor modifications. Four carcinoma cell lines (MDAMB-231, MDA-MB-175, MDA-MB-453 and SK-BR-3) from the Oracle HER2 Control Slide (Leica Biosystems), with a known HER2 gene status, were also used as a control of the FISH assays and analyzed for HER2 and $T O P 2 A$ genomic status.

\section{FISH evaluation}

For all probes, sequential ( 5 planes at $1.0 \mu \mathrm{m}$ ) digital images were captured using the Plan Apo VC 100x/1.40 oil objective (Nikon, Japan) using specific filters for each probe. The resulting images were reconstructed using specifically developed software for cytogenetics (XCytoGen, ALPHELYS, Plaisir, France). For the evaluation of HER2/TOP2A/CEN17 status, non-overlapping nuclei from the invasive part of the tumor were randomly selected, according to morphological criteria using DAPI staining, and scored (M.B.). The virtual slides of HER2, ER or PgR stains, created as previously described [31], were used for selecting the invasive part of the tumor in each TMA. Twenty tumor nuclei were counted according to Press et al. [13]. The HER2 gene was considered to be amplified when the ratio of the respective gene probe/centromere probe was $\geq 2.2$ [27] and deleted when the ratio was $<0.75$. The TOP $2 A$ gene was considered to be amplified when the ratio of the respective gene probe/CEN17 probe was $\geq 2.0$ and deleted when the ratio was $<0.8$ [32]. In cases with values at or near the cut-off (1.8-2.2 for amplifications and 0.7-0.9 for deletions), additional 20 or 40 nuclei were counted and the ratio was recalculated. In cases with a borderline ratio at 60 nuclei, additional FISH assays were performed in whole sections. All primary image data of the TMA and whole tumor sections have been digitally scanned and made publicly available at: http://www.hecog-images.gr/readDir.php?nextdir=TOP2AtrastuzumabMBC.

\section{Single nucleotide polymorphism (SNP) genotyping for PIK3CA mutations}

DNA was extracted from 182 FFPE whole tissue sections or macrodissected tissue fragments containing $>70 \%$ tumor cells, using a fully automated isolation method based on silica-coated magnetic beads (Versant Tissue Preparation Reagents, Siemens Healthcare Diagnostics, Tarrytown, NY) in combination with a liquid handling robot, as previously described [33]. Mutation testing for PIK3CA E542K and E545K (exon 9) and H1047R (exon 20) was accomplished with custom Taqman-MGB-SNP genotyping assays (duplex q-PCR for the detection of control DNA and mutant target in the same reaction), as previously described [22].

\section{Statistical analysis}

Data on selected patient and tumor characteristics, previous and subsequent lines of treatment, disease progression, events and survival were obtained from medical records and entered into a central database. Follow-up information was updated in February 2010. Associations between the examined markers were performed in the total cohort using the chi-square or Fisher's exact tests where appropriate. The majority of patients received trastuzumab in the 1st line of treatment for metastatic disease and thus time to progression (TTP) was defined as the time from trastuzumab initiation in the 1st line of treatment (with or without concurrent chemo/hormonal therapy) to the date of documented disease progression. Survival was measured from the initiation of trastuzumab treatment in patients receiving trastuzumab as a 1st line treatment to the date of death. Patients alive were censored at the date of the last follow-up contact. Survival probabilities were estimated by the Kaplan-Meier method and compared using the log-rank test. For the univariate and multivariate analyses, Cox proportional hazards models were used. Univariate analyses were performed separately in HER2positive and HER2-negative patients, while multivariate analyses were performed in the total cohort and in the population of clinical interest, i.e. the HER2-positive patients. Interaction tests for the examined markers (TOP2A gene status and Topolla protein expression) with HER2 and ER/PgR status were performed. We also examined the interaction of the examined markers with anthracycline-containing treatment in the adjuvant and/ or the 1st line metastatic setting. In the multivariate setting, model choice was performed using backward 
selection criteria with $\mathrm{p}<0.10$, including in the initial step clinico-pathological parameters, such as age ( $>60$ vs. $50-$ 60 vs. $<50$ ), menopausal status (post vs. pre), performance status (1-2 vs. 0$)$, number of metastatic sites $(\geq 3$ vs. $<3$ ), anthracycline treatment (yes vs. no), hormonal receptor status (ER/PgR) (positive vs. negative), Ki67 protein expression (high vs. low), HER2 status (positive vs. negative), TOP2A gene status (deleted vs. nonamplified vs. amplified) and TopoIla protein expression (positive vs. negative). Multivariate analyses were performed in the total cohort and in the HER2-positive subgroup and were presented by forest plots. All tests were two-sided at the $\alpha=0.05$ level of significance. No adjustment for multiple comparisons was performed. Results of this study were presented according to reporting recommendations for tumor marker prognostic studies [34]. The SPSS (version 15.0, IBM Corporation, Armonk, NY) and SAS (version 9.3, SAS Institute Inc., Cary, NC) software were used for statistical analysis.

\section{Results}

Among the 225 eligible patients with metastatic breast cancer treated with trastuzumab, only 137 (61\%) were found to have centrally assessed HER2 gene amplification by FISH and/or 3+ HER2 protein overexpression by IHC (Figure 1). It is of note that all 225 patients were considered to be HER2-positive when assessed with IHC (and FISH in some cases) at the local laboratories and had therefore been treated with trastuzumab. Selected patient and tumor characteristics from the 225 patients, at trastuzumab initiation, are presented in Table 1.

Trastuzumab was given as 1st line treatment in 191 patients $(85 \%)$, while in $15 \%$ of the patients trastuzumab was initiated later in the course of metastatic disease. The majority of the 1st line treated patients received it in combination with chemotherapy (186 patients, 97\%), while the rest (5 patients, $3 \%$ ) received trastuzumab as monotherapy. Most of the patients received a taxane in the 1st line setting in addition to trastuzumab (137 patients, 72\%), while 27 patients (14\%) received anthracyclines.

Median follow-up for all patients was 66 months, while for patients treated with trastuzumab in the 1st line median follow-up was 51 months. Totally, 137 patients died among all patients, while 151 of the 191 patients treated with trastuzumab in the 1st line demonstrated tumor progression. Median survival was significantly longer in HER2-positive patients treated with trastuzumab (median survival 50.4 months, 95\% Confidence Interval [CI]: 39.4-61.4) compared to HER2-negative patients (median survival 35.3 months, 95\% CI: 30.9-39.6, log-rank, $\mathrm{p}=0.007)$. TTP was 14 months (95\% CI: 9.6-18.5) for HER2-positive patients treated with 1st line trastuzumab, as compared to 10.3 months $(95 \% \mathrm{CI}$ : 5.6-15.0) for HER2-negative patients. This difference was not statistically significant (log-rank, $\mathrm{p}=0.24$ ), probably due
Table 1 Selected patient and tumor characteristics (at trastuzumab initiation) according to HER2 status

\begin{tabular}{|c|c|c|}
\hline & \multicolumn{2}{|c|}{ HER2 status } \\
\hline & Positive & Negative \\
\hline $\mathbf{N}$ & 137 & 88 \\
\hline \multicolumn{3}{|l|}{$\overline{\text { Age (years) }}{ }^{1}$} \\
\hline \multirow[t]{2}{*}{ Median (range) } & $54.6(28.4-95.0)$ & $58.9(31.8-78.8)$ \\
\hline & N (\%) & N (\%) \\
\hline \multicolumn{3}{|l|}{ Menopausal status } \\
\hline Premenopausal & $43(31.4)$ & $26(29.5)$ \\
\hline Postmenopausal & $94(68.6)$ & $62(70.5)$ \\
\hline \multicolumn{3}{|l|}{ Performance status } \\
\hline 0 & $96(70.1)$ & $56(63.6)$ \\
\hline 1 & $28(20.4)$ & $18(20.5)$ \\
\hline 2 & $5(3.6)$ & $7(8.0)$ \\
\hline Unknown & $8(5.8)$ & $7(7.8)$ \\
\hline History of adjuvant $\mathrm{CT}$ & $75(54.7)$ & $55(62.5)$ \\
\hline Anthracycline containing & $59(43.1)$ & $29(33.0)$ \\
\hline Taxane containing & $36(26.3)$ & $17(19.3)$ \\
\hline CMF-like & $42(30.7)$ & $30(34.1)$ \\
\hline History of adjuvant HT & $61(44.5)$ & $42(47.7)$ \\
\hline History of adjuvant RT & $52(38.0)$ & $33(37.5)$ \\
\hline \multicolumn{3}{|c|}{ Tumor grade (initial diagnosis) } \\
\hline 1 & $4(2.9)$ & $2(2.3)$ \\
\hline 2 & $48(35.0)$ & $36(40.9)$ \\
\hline 3 & $75(54.7)$ & $42(47.7)$ \\
\hline Unknown & $10(7.3)$ & $8(9.1)$ \\
\hline \multicolumn{3}{|l|}{ Site of metastases } \\
\hline Locoregional & $45(32.8)$ & $28(31.8)$ \\
\hline Distant & $117(85.4)$ & $78(88.6)$ \\
\hline Only locoregional & $10(7.3)$ & $5(5.7)$ \\
\hline Only distant & $82(59.9)$ & $55(62.5)$ \\
\hline Bones & $54(39.4)$ & $37(42.0)$ \\
\hline Visceral & $93(67.9)$ & $58(65.9)$ \\
\hline \multicolumn{3}{|l|}{ Number of metastatic sites } \\
\hline 1 & $54(39.4)$ & $28(31.8)$ \\
\hline 2 & $40(29.2)$ & $30(34.1)$ \\
\hline$\geq 3$ & $38(27.7)$ & $25(28.4)$ \\
\hline Unknown & $5(3.6)$ & $5(5.7)$ \\
\hline History of 1st line CT & $123(89.8)$ & $68(77.3)$ \\
\hline Anthracycline containing & $18(13.1)$ & $9(10.2)$ \\
\hline \multicolumn{3}{|c|}{ Number of treatment lines with $T$} \\
\hline 1 & $51(37.2)$ & $39(44.3)$ \\
\hline 2 & $33(24.1)$ & $19(21.6)$ \\
\hline 3 & $23(16.8)$ & $12(13.6)$ \\
\hline$\geq 4$ & $30(21.9)$ & $18(20.5)$ \\
\hline
\end{tabular}

${ }^{1} \mathrm{p}=0.019$; CT chemotherapy, $H T$ hormonal therapy, $R T$ radiotherapy, $T$ trastuzumab.

HER2-positive: HER2 amplification by FISH and/or HER2 3+ by IHC. 
to the small number of patients. ER, PgR, Ki67, PTEN and PIK3CA data were presented in detail in a previous publication [22].

\section{Associations between examined markers}

TOP2A gene alterations were assessed in 221 tumors, $25 \%$ of which were amplified and $12 \%$ were deleted. Tumors that were not TOP $2 A$ amplified or deleted were analyzed as a separate group (TOP $2 A$ non-amplified tumors). As expected, $T O P 2 A$ gene amplification and HER2-negative status were mutually exclusive. Representative FISH images of the evaluated cell lines and invasive breast carcinoma cases are presented in Figure 2. The majority of TOP $2 A$ gene deletions were seen in the HER2-positive group (21 of the 26 cases), while $43 \%$ of HER2-positive tumors were not amplified for TOP2A (Table 2). A significant association of TOP2A gene status with HER2 status was found (Fisher's exact test, $\mathrm{p}<0.001)$. Moreover, TOP $2 A$ gene amplification was more frequent in ER-negative tumors (28\% in ER-negative vs. $24 \%$ in ER-positive, $\mathrm{p}=0.017$ ), whereas no such association was found with Ki67 $(\mathrm{p}=0.47)$ or PTEN protein expression $(\mathrm{p}=0.12)$. TOP $2 A$ gene amplification was negatively associated with the presence of PIK3CA mutations $(28 \%$ in WT vs. $14 \%$ in mutated, $\mathrm{p}=0.035)$, the distribution however, of PIK3CA mutations in the HER2positive group did not differ between TOP $2 A$ amplified and non-amplified tumors ( $12 \%$ vs. $23 \%, \mathrm{p}=0.25$ ).

Concerning TopoIIa protein expression, the majority of cases were positive (125 of 193 cases assessed, 65\%), but no association with HER2 status was found $(\mathrm{p}=0.65)$. TopoIIa protein positivity was associated with ERpositive status (72\% in ER-positive vs. $49 \%$ in ER-negative, $\mathrm{p}=0.005)$, high Ki67 expression (68\% in high vs. $32 \%$ in low, $\mathrm{p}=0.004)$ and positive PTEN protein status $(80 \%$ in positive vs. $58 \%$ in negative, $\mathrm{p}=0.003$ ). The majority of the PIK3CA mutations in this cohort (28 of 34 ) were encountered in tumors with positive Topolla protein expression $(\mathrm{p}=0.015)$.

For 189 tumors, both TOP2A gene status and Topolla protein expression were assessed (Figure 1), but no significant association was found between the two $(\mathrm{p}=0.11)$. More specifically, 37 among 49 TOP2A amplified tumors were Topolla-positive (76\%), while 73 among 117 TOP2A non-amplified tumors were Topolla-positive (62\%). TOP2A gene deletions were equally distributed according to Topolla protein expression (11 TopoIIanegative cases vs. 12 Topolla-positive cases).

\section{Effects of TOP2A gene alterations and Topolla protein expression on the outcome of MBC patients treated with trastuzumab}

Survival analysis was performed in the 1st line treated subpopulation (191 of the 225 patients treated with trastuzumab), as defined in the statistical analysis section. Since TOP2A gene amplification and HER2negativity were found to be mutually exclusive, we examined in univariate analysis the association of TOP2A gene status with outcome in the HER2-positive subgroup only. TOP2A gene status was not associated with TTP (Wald's $\mathrm{p}=0.14$ ), however, TOP $2 A$ nonamplified and deleted tumors were associated with increased risk for death (Hazard Ratio $[\mathrm{HR}]=2.16,95 \%$ CI: $1.20-3.88$, Wald's $\mathrm{p}=0.010$ and $\mathrm{HR}=2.67,95 \% \mathrm{CI}$ : $1.27-5.62, \mathrm{p}=0.009$, respectively) compared to amplified tumors (Table 3 ).

Topolla protein expression was not associated with either TTP (Wald's $\mathrm{p}=0.80$ for HER2-positive and $\mathrm{p}=0.98$ for HER2-negative patients) or survival (Wald's $\mathrm{p}=0.22$ for HER2-positive and $\mathrm{p}=0.30$ for HER2-negative patients). Tests for interaction of TopoIIa protein expression with HER2 status were not significant (Wald's $\mathrm{p}>0.05$, for both TTP and survival). Interaction tests of TOP2A gene status with HER2 status were not applicable, since TOP2A gene amplification and HER2negativity were found to be mutually exclusive.

Since, subgroups defined by ER/PgR status are of clinical interest, we also examined whether there was a significant interaction between ER/PgR status and TOP2A gene status or Topolla protein expression. No significant interactions were found (Wald's p values $>0.05$ ).

\section{Interaction of TOP2A gene alterations with anthracycline treatment}

In the multivariate setting, we examined the predictive role of TOP $2 A$ gene expression to anthracycline treatment administered either in the adjuvant or the 1st line metastatic setting. Ninety-three patients received anthracyclines as adjuvant and/or 1st line treatment. The majority of them (64 cases, 69\%) were HER2-positive. Concerning TOP2A gene expression in the anthracyclinetreated/HER2-positive subgroup, 25 patients were amplified, 29 were non-amplified and 10 cases had a TOP2A deletion.

In the HER2-positive subgroup, a significant interaction of TOP2A with anthracycline treatment (either in the adjuvant or the 1st line setting) was observed both for TTP (Wald's $\mathrm{p}=0.055$ ) and survival (Wald's $\mathrm{p}=0.015$ ), while no clinicopathological parameters were retained in the final model (Figure 3). In terms of TTP (Figure 3A), among the TOP $2 A$ deleted subgroup, anthracyclinetreated patients were associated with increased risk for progression, while in terms of survival (Figure $3 \mathrm{~B}$ ), among the TOP $2 A$ amplified subgroup, anthracyclinetreated patients were associated with decreased risk for death. No significant interactions were found between TopolIa protein expression and anthracycline treatment (Wald's p values $>0.05$ ). 


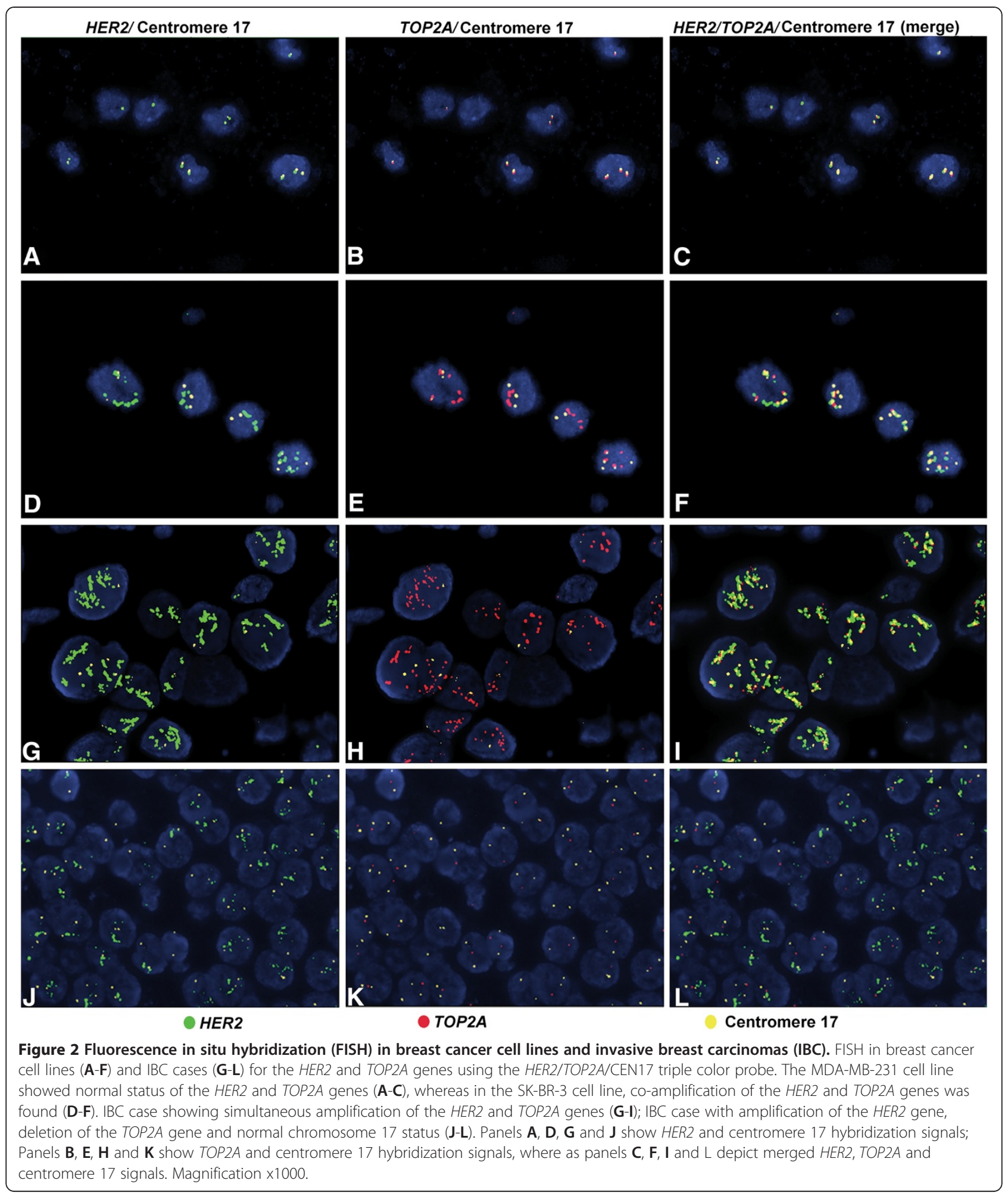

In parallel, for patients not treated with anthracyclines there were no significant differences in TTP between deleted and non-amplified versus amplified tumors (HR=0.76, 95\% CI: 0.29-1.96, Wald's $\mathrm{p}=0.57$ and $\mathrm{HR}=1.23, \quad 95 \% \quad \mathrm{CI}: \quad 0.61-2.47, \quad \mathrm{p}=0.56$, respectively)
(Figure 4A). For anthracycline-treated patients, deleted and non-amplified tumors were associated with increased risk for progression compared to amplified tumors ( $\mathrm{HR}=3.42,95 \% \quad \mathrm{CI}: 1.57-7.46$, Wald's $\mathrm{p}=0.002$ and $\mathrm{HR}=1.83, \quad 95 \% \quad \mathrm{CI}: 1.00-3.34, \quad \mathrm{p}=0.050$, respectively) 
Table 2 Association of TOP2A and Topolla with HER2 status

\begin{tabular}{|c|c|c|c|c|c|c|}
\hline & & \multicolumn{4}{|c|}{ HER2 status } & \multirow[t]{3}{*}{ Fisher's exact $p$} \\
\hline & & \multicolumn{2}{|c|}{ Positive } & \multicolumn{2}{|c|}{ Negative } & \\
\hline & & $\mathbf{N}$ & $\%$ & $\mathrm{~N}$ & $\%$ & \\
\hline \multirow[t]{3}{*}{ TOP2A (FISH) $n=221$} & Amplified & 55 & 41.0 & 0 & 0 & $<0.001$ \\
\hline & Deleted & 21 & 15.7 & 5 & 5.7 & \\
\hline & Non-amplified & 58 & 43.3 & 82 & 94.3 & \\
\hline \multirow[t]{2}{*}{ Topolla $(\mathrm{IHC}) \mathrm{n}=193$} & Negative & 39 & 33.9 & 29 & 37.2 & 0.65 \\
\hline & Positive & 76 & 66.1 & 49 & 62.8 & \\
\hline
\end{tabular}

(Figure 4B). Similarly, in terms of survival the same associations were observed. Among anthracycline-treated patients, TOP $2 A$ deleted and non-amplified tumors had increased risk for death compared to amplified tumors $(\mathrm{HR}=6.94,95 \% \quad \mathrm{CI}:$ 2.26-21.34, Wald's $\mathrm{p}=0.001$ and $\mathrm{HR}=5.33, \quad 95 \% \quad \mathrm{CI}:$ 2.02-14.12, $\mathrm{p}=0.001$, respectively) (Figure 4D). In patients not treated with anthracyclines no such differences in survival were observed (Figure 4C). In the contrary, no significant differences in TTP and survival were observed between anthracycline- and nonanthracycline-treated patients in the HER2-positive subgroup when TOP $2 A$ gene status was not taken into account (log-rank, $\mathrm{p}=0.67$ for TTP and $\mathrm{p}=0.57$ for survival).

Repeating the analysis in HER2-positive patients that had received anthracyclines in the adjuvant setting (52 of the 64 anthracycline-treated/HER2-positive patients) the results were identical to the ones presented in Figure 3. Among the TOP $2 A$ deleted subgroup, adjuvant anthracycline-treated patients were associated with increased risk for progression $(\mathrm{HR}=3.25,95 \% \mathrm{CI}$ : 1.16 9.09, Wald's $\mathrm{p}=0.025)$, while among the TOP $2 A$ amplified subgroup, adjuvant anthracycline-treated patients were associated with decreased risk for death $(\mathrm{HR}=0.27$, 95\% CI: 0.08-0.94, Wald's p=0.041).

In multivariate analysis of the total cohort, the significance of TOP2A in anthracycline-treated patients remained, resulting in similar associations for both TTP and survival (Additional file 1 and Additional file 2) to the ones seen in the HER2-positive subgroup.

Finally, when examining in the models any TOP $2 A$ alteration (deletions or amplifications) versus nonamplification, the interaction with anthracycline treatment was significant only in the case of the HER2-positive subgroup in terms of survival $(\mathrm{p}=0.042)$, while among the anthracycline-treated patients, tumors with $T O P 2 A$ alterations were associated with improved survival compared to the non-amplified tumors.

\section{Discussion}

To our knowledge, the present study is one of the first to evaluate the role of $T O P 2 A$ gene amplification and Topolla protein expression in the outcome of patients treated with trastuzumab-based regimens for $\mathrm{MBC}$. The most important evidence provided herein is that $T O P 2 A$ gene amplification is a favorable prognostic

Table 3 Univariate Cox regression models for TOP2A expression according to HER2 status

\begin{tabular}{|c|c|c|c|c|c|c|c|c|}
\hline & \multicolumn{4}{|c|}{ HER2-positive } & \multicolumn{4}{|c|}{ HER2-negative } \\
\hline & Events & HR & $95 \% \mathrm{Cl}$ & Wald's p & Events & HR & $95 \% \mathrm{Cl}$ & Wald's p \\
\hline \multicolumn{9}{|l|}{ TTP } \\
\hline \multicolumn{9}{|l|}{ TOP2A (FISH) } \\
\hline Deleted vs. Amplified & 16 vs. 36 & 1.58 & $0.87-2.87$ & 0.13 & & & & \\
\hline Non-amplified vs. Amplified & 43 vs. 36 & 1.51 & $0.96-2.37$ & 0.07 & & & & \\
\hline \multicolumn{9}{|l|}{ Topolla (IHC) } \\
\hline Positive vs. Negative & 57 vs. 27 & 0.94 & $0.60-1.49$ & 0.80 & 31 vs. 17 & 1.01 & $0.55-1.83$ & 0.98 \\
\hline \multicolumn{9}{|l|}{ Survival } \\
\hline \multicolumn{9}{|l|}{ TOP2A (FISH) } \\
\hline Deleted vs. Amplified & 12 vs. 17 & 2.67 & $1.27-5.62$ & 0.009 & & & & \\
\hline Non-amplified vs. Amplified & 33 vs. 17 & 2.16 & $1.20-3.88$ & 0.010 & & & & \\
\hline \multicolumn{9}{|l|}{ Topolla (IHC) } \\
\hline Positive vs. Negative & 38 vs. 19 & 0.71 & $0.41-1.24$ & 0.22 & 23 vs. 14 & 0.70 & $0.36-1.37$ & 0.30 \\
\hline
\end{tabular}

$\mathrm{Cl}$ confidence interval, $H R$ hazard ratio, TTP time to progression.

Empty cells: Non-applicable. 


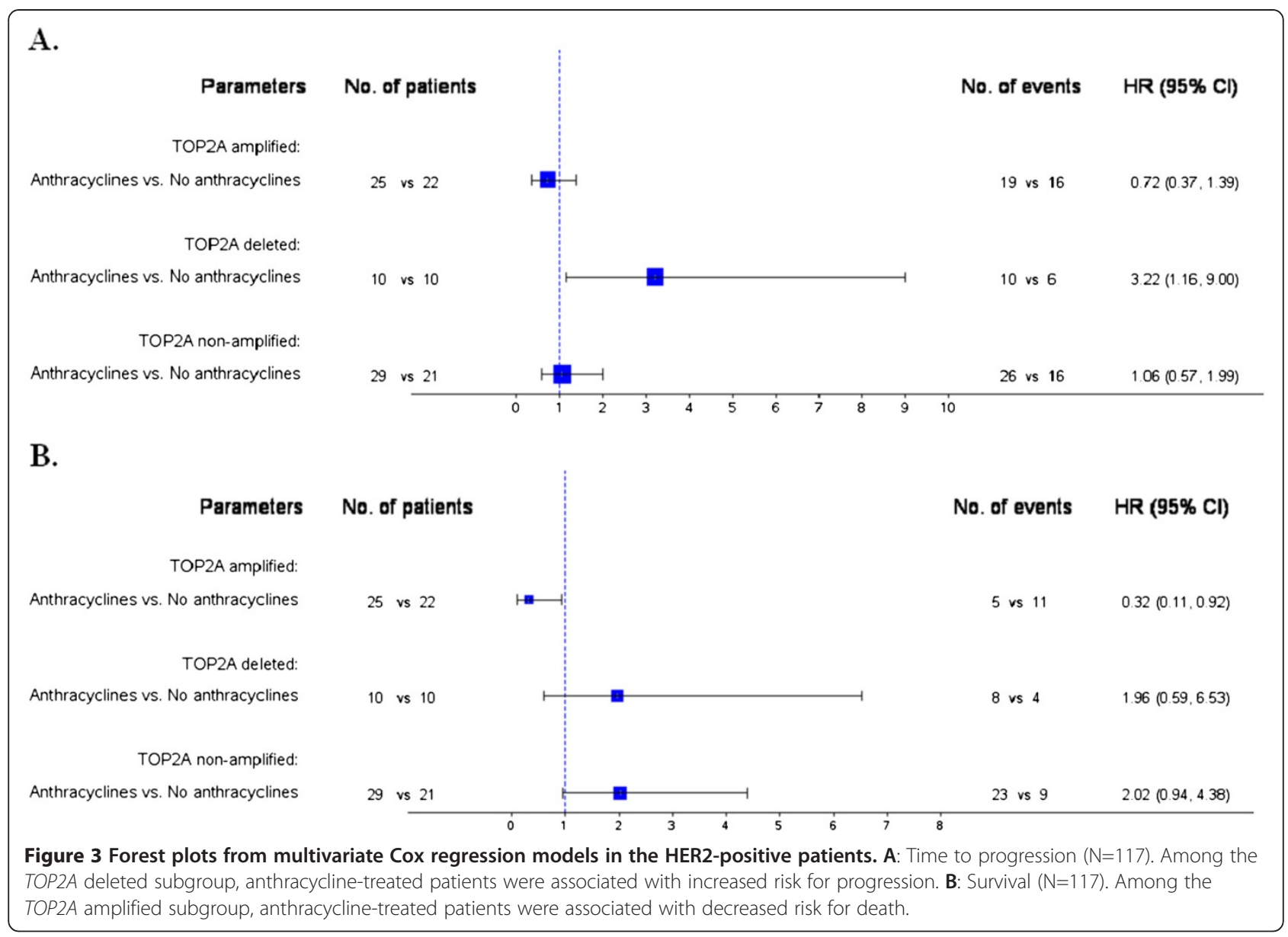

factor in HER2-positive patients treated with trastuzumab. Patients with HER2-positive/TOP2A non-amplified or deleted tumors did not seem to benefit from trastuzumab-based regimens and had an unfavorable outcome compared to TOP $2 A$ amplified tumors, in line with recent reports on TOP $2 A$ gene dosage [35] and TOP $2 A$ gene amplification [36].

The role of the TOP $2 A$ gene has mainly been examined in relation to anthracycline treatment. Coamplification of HER2 and TOP2A was associated with favorable response to anthracycline-based therapy of locally advanced breast cancer [12]. The results of our study did not appear, at first, to be associated with the administration of anthracyclines, since only $12 \%$ of our patients had received such treatment in the 1st line metastatic setting. However, $39 \%$ of all patients and $43 \%$ of the HER2-positive ones had received anthracyclines in the adjuvant setting. Upon further analysis of our data, taking into account adjuvant and/or 1st line anthracycline treatment, a significant interaction of TOP $2 A$ with anthracycline treatment was observed both for TTP and survival. In terms of survival among the $T O P 2 A$ amplified subgroup, anthracycline-treated patients were associated with decreased risk for death. It appears therefore that the improvement in survival of the TOP $2 A$ amplified subgroup treated with trastuzumab is probably due to the concurrent or previous exposure of the patients to anthracyclines, rather than the effect of the trastuzumab treatment itself. Furthermore, when TOP $2 A$ amplified patients treated with anthracyclines in the adjuvant setting were analyzed separately, they were found to have decreased risk for death, suggesting that even history of adjuvant anthracycline treatment results in survival advantage of $T O P 2 A$ amplified patients treated with trastuzumab.

There is a very recent report from the Breast Cancer International Research Group (BCIRG) 006 trial [37] and an additional retrospective analysis of almost 5,000 patients [13] regarding the efficacy of trastuzumab in breast cancer patients with HER2 and TOP2A coamplification. The first study is one of the largest randomized trials, which confirmed the role of trastuzumab in the adjuvant setting. The most interesting aspect of the BCIRG 006 trial is that it included a nonanthracycline regimen (docetaxel, carboplatin and trastuzumab), which was compared to AC-T (doxorubicin, 


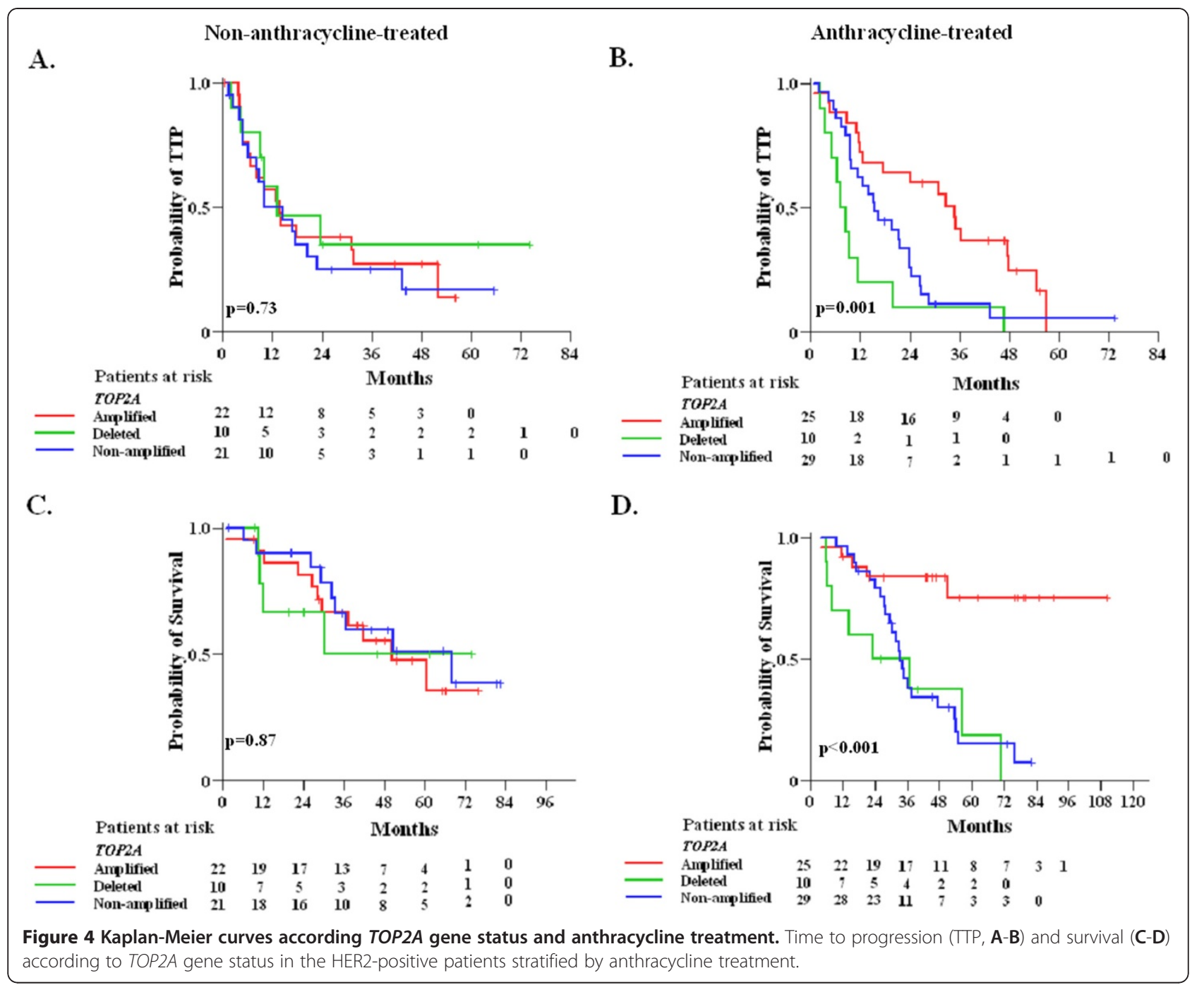

cyclophosphamide, followed by docetaxel) with or without trastuzumab. This study demonstrated that the DFS benefit conferred by AC-T without trastuzumab in HER2-positive breast cancer patients is actually restricted to TOP $2 A$ co-amplified malignancies, which constituted a subset (35\%) of the HER2-positive cancers, and is virtually indistinguishable from the benefit achieved by the addition of trastuzumab. Importantly, this same benefit (found in the TOP $2 A$ co-amplified subset) could also be attained by a non-anthracycline regimen in combination with trastuzumab, thus avoiding the toxicities seen with anthracyclines. In our study, trastuzumab was given to advanced-stage HER2-positive breast cancer patients in the metastatic setting, our findings should not therefore be compared to those of the BCIRG 006 trial [37].

Recent studies support the role of Topolla protein expression, rather than $T O P 2 A$ gene amplification, as a predictor of response to anthracycline-based chemotherapy in the adjuvant setting [16]. It is of note, that TopoIIa protein overexpression has been reported in HER2-positive, as well as HER2-negative tumors, independently of TOP2A gene amplification [38]. The latter finding has also been shown in our study; TopolIa protein overexpression however, was not associated with either TTP or survival.

TopolIa protein overexpression was however associated with ER-positive status and high Ki67 expression, partly in line with previous reports, since Topolla protein expression had been shown to be associated with ER-positive status [39] and the Ki67 proliferation index [40]. To the best of our knowledge, the associations between Topolla and PTEN protein expression, as well as PIK3CA mutation presence are new findings in breast cancer tissue series, meriting further investigation for their biological importance. Of note, Topolla protein is upregulated in proliferating normal and cancer cells, in order to participate in the cell duplication process [41]. 
Hence, with the widely used cut-off of $5 \%$ positive neoplastic cells to assess TopoIIa protein positivity, tumors are found to be positive for Topolla in the absence of underlying amplification of the corresponding gene.

Alterations of the TOP $2 A$ gene mostly happen in HER2-positive tumors, however TOP2A does not always follow the amplification fate or rate of the HER2 amplicon, since it is not always included in the so called "smallest region of amplification" next to HER2 [36,42], while it may also be deleted in the presence of HER2 amplification, as observed here and elsewhere [10]. Thus, at least in a subset of TOP $2 A$ amplified tumors, the mechanism driving TOP2A amplification may be different than the one resulting in $H E R 2$ amplification $[9,10,43]$, as shown by the far lower ratio of TOP2A signals in comparison to HER2 signals [10]. In addition, TOP2A may also be amplified or deleted in the absence of HER2 amplification, further supporting the view of distinct and possibly multiple mechanisms, resulting in alterations of this gene. The absence of TOP $2 A$ amplification and the presence of deletions may practically have the same unfavorable impact on the outcome of HER2positive patients, as shown in this study. With respect to gene deletions, it should be noted that the way markers are scored with FISH on FFPE sections it is unavoidable to obtain false positive results (deletions), due to nuclear truncations that interfere with the number of fluorescent signals to be counted per nucleus in a mostly unpredictable manner. Hence, although TOP2A gene deletions may indeed occur, the results concerning this FFPEFISH marker, in the present and in the previously published studies, should be interpreted with caution.

In most of the published series, TOP $2 A$ gene amplification or deletion was a rare event in HER2-negative patients [44]. Only in four studies $[10,16,18,45]$, the rate of TOP $2 A$ alterations was considerably greater than the $1 \%$ to $2 \%$ range reported in all other studies. In line with the majority of the published data we did not find HER2-negative patients with $T O P 2 A$ gene amplification.

\section{Conclusions}

In conclusion our study is one of the first to examine the role of the TOP2A gene in the field of trastuzumabbased treatment in MBC. We have evaluated the role of $T O P 2 A$ gene amplification and TopoIIa protein expression and we have shown that TOP2A gene amplification is a favorable prognostic factor in HER2-positive MBC patients treated with trastuzumab, such an effect however, appears to rather be related to treatment with anthracyclines. In advanced-stage HER2-positive breast cancer patients treated with trastuzumab, TOP2A amplification appears to be a strong predictive factor for improved survival in patients with concurrent or previous exposure to anthracyclines. Nevertheless, given the small size and the retrospective nature of our study, these data have to be viewed as hypothesis generating and need to be further explored and validated in larger cohorts of patients treated in the context of randomized trials. We are currently investigating these associations in patients included in a large adjuvant phase III trial conducted by our Group.

\section{Additional files}

\section{Additional file 1: Forest plots from multivariate Cox regression models in the total study population: time to progression $(A, n=181)$ and survival $(B, n=172)$. \\ Additional file 2: Kaplan-Meier curves for time to progression (TTP, A-B) and survival (C-D) according to TOP2A gene status in the total study population stratified by anthracycline treatment.}

\section{Abbreviations}

CEN17: Centromere 17; Cl: Confidence interval; ER: Estrogen receptor; FFPE: Formalin-fixed paraffin-embedded; HER2: Human epidermal growth factor receptor 2; HR: Hazard ratio; IHC: Immunohistochemistry; Ki67: Antigen Ki67; MBC: Metastatic breast cancer; OS: Overall survival; PIK3CA: Phosphoinositide-3-kinase, catalytic, alpha polypeptide; PFS: Progression-free survival; PgR: Progesterone receptor; PTEN: Phosphatase and tensin homolog deleted on chromosome 10; SNP: Single nucleotide polymorphism; TOP2A: Topoisomerase II alpha (gene amplification); Topolla: Topoisomerase II alpha (protein expression); TTP: Time to progression; TMA: Tissue microarray.

\section{Competing interests}

The authors declare that they have no competing interests.

\section{Authors' contributions}

GF conceived of the study, participated in its design and coordination, participated in the clinical management of the patients, contributed to the collection of the tumor tissue samples analyzed in the study and drafted the manuscript. CC conceived of the study, participated in its design and coordination, participated in the clinical management of the patients, contributed to the collection of the tumor tissue samples analyzed in the study and drafted the manuscript. MB carried out the TMA construction and the IHC and FISH assays and helped to draft the manuscript. VK carried out the molecular studies and helped to draft the manuscript. AGE performed the statistical analysis and helped to draft the manuscript. IX participated in the clinical management of the patients and contributed to the collection of the tumor tissue samples analyzed in the study. AB carried out the

immunoassays. GP participated in the clinical management of the patients and contributed to the collection of the tumor tissue samples analyzed in the study. NX participated in the clinical management of the patients and contributed to the collection of the tumor tissue samples analyzed in the study. IP carried out the immunoassays. AK participated in the clinical management of the patients and contributed to the collection of the tumor tissue samples analyzed in the study. PP participated in the clinical management of the patients and contributed to the collection of the tumor tissue samples analyzed in the study. DB participated in the clinical management of the patients and contributed to the collection of the tumor tissue samples analyzed in the study. DVS participated in the clinical management of the patients and contributed to the collection of the tumor tissue samples analyzed in the study. KTK conceived of the study, participated in its design and coordination and drafted the manuscript. All authors read and approved the final manuscript.

\section{Acknowledgements}

This work has been presented in part at the $33^{\text {rd }}$ Annual San Antonio Breast Cancer Symposium, December 8-12, 2010. The authors are deeply indebted to all patients who provided biological material for research purposes. We would like to thank Thalia Spinari for coordinating tissue sample collection, Dimitra Katsala for monitoring the study, Maria Moschoni for coordinating 
data management and Stella Dallidou for secretarial assistance. Supported by a Hellenic Cooperative Oncology Group research grant (HE TR_10).

\section{Author details}

'Department of Medical Oncology, "Papageorgiou" Hospital, Aristotle University of Thessaloniki School of Medicine, 564 03, Thessaloniki, Macedonia, Greece. ${ }^{2}$ Second Department of Medical Oncology, "Metropolitan" Hospital, Athens, Greece. ${ }^{3}$ Laboratory of Molecular Oncology, Hellenic Foundation for Cancer Research, Aristotle University of Thessaloniki School of Medicine, Thessaloniki, Greece. ${ }^{4}$ Department of Pathology, Aristotle University of Thessaloniki School of Medicine, Thessaloniki, Greece. ${ }^{5}$ Section of Biostatistics, Hellenic Cooperative Oncology Group, Data Office, Athens, Greece. ${ }^{6}$ Department of Pathology, loannina University Hospital, loannina, Greece. ${ }^{7}$ Department of Medical Oncology, loannina University Hospital, Ioannina, Greece. ${ }^{8}$ Oncology Section, Second Propaedeutic Department of Internal Medicine, University General Hospital "Attikon", Athens, Greece. "Histopathology Department, "Alexandra" Hospital, Athens, Greece.

${ }^{10}$ Department of Medical Oncology, "Hippokration" Hospital, Athens, Greece.

${ }^{11}$ First Department of Medical Oncology, "Metropolitan" Hospital, Athens, Greece. ${ }^{12}$ Translational Research Section, Hellenic Cooperative Oncology Group, Data Office, Athens, Greece.

Received: 31 May 2012 Accepted: 16 October 2012

Published: 23 October 2012

\section{References}

1. Dafni U, Grimani I, Xyrafas A, Eleftheraki AG, Fountzilas G: Fifteen-year trends in metastatic breast cancer survival in Greece. Breast Cancer Res Treat 2010, 119:621-631.

2. Gennari A, Conte P, Rosso R, Orlandini C, Bruzzi P: Survival of metastatic breast carcinoma patients over a 20-year period: a retrospective analysis based on individual patient data from six consecutive studies. Cancer 2005, 104:1742-1750.

3. Andrulis IL, Bull SB, Blackstein ME, Sutherland D, Mak C, Sidlofsky S, Pritzker KP, Hartwick RW, Hanna W, Lickley L, et al: neu/erbB-2 amplification identifies a poor-prognosis group of women with node-negative breast cancer. Toronto Breast Cancer Study Group. Journal of clinical oncology: official journal of the American Society of Clinical Oncology 1998, 16:1340-1349.

4. Slamon DJ, Godolphin W, Jones LA, Holt JA, Wong SG, Keith DE, Levin WJ, Stuart SG, Udove J, Ullrich A, et al: Studies of the HER-2/neu proto-oncogene in human breast and ovarian cancer. Science 1989, 244:707-712.

5. Cobleigh MA, Vogel CL, Tripathy D, Robert NJ, Scholl S, Fehrenbacher L, Wolter JM, Paton V, Shak S, Lieberman G, Slamon DJ: Multinational study of the efficacy and safety of humanized anti-HER2 monoclonal antibody in women who have HER2-overexpressing metastatic breast cancer that has progressed after chemotherapy for metastatic disease. Journal of clinical oncology: official journal of the American Society of Clinical Oncology 1999, 17:2639-2648.

6. Slamon DJ, Leyland-Jones B, Shak S, Fuchs H, Paton V, Bajamonde A, Fleming T, Eiermann W, Wolter J, Pegram M, et al: Use of chemotherapy plus a monoclonal antibody against HER2 for metastatic breast cancer that overexpresses HER2. N Engl J Med 2001, 344:783-792.

7. Tsai-Pflugfelder M, Liu LF, Liu AA, Tewey KM, Whang-Peng J, Knutsen T, Huebner $\mathrm{K}$, Croce CM, Wang JC: Cloning and sequencing of cDNA encoding human DNA topoisomerase II and localization of the gene to chromosome region 17q21-22. Proc Natl Acad Sci U S A 1988, 85:7177-7181.

8. Jacobson KK, Morrison LE, Henderson BT, Blondin BA, Wilber KA Legator MS, O'Hare A, Van Stedum SC, Proffitt JH, Seelig SA, Coon JS: Gene copy mapping of the ERBB2/TOP2A region in breast cancer. Genes Chromosomes Cancer 2004, 40:19-31.

9. Arriola E, Marchio C, Tan DS, Drury SC, Lambros MB, Natrajan R, Rodriguez-Pinilla SM, Mackay A, Tamber N, Fenwick K, et al: Genomic analysis of the HER2/TOP2A amplicon in breast cancer and breast cancer cell lines. Laboratory investigation; a journal of technical methods and pathology 2008, 88:491-503.

10. Nielsen KV, Muller S, Moller S, Schonau A, Balslev E, Knoop AS, Ejlertsen B: Aberrations of ERBB2 and TOP2A genes in breast cancer. Mol Oncol 2010, 4:161-168.
11. Capranico G, Butelli E, Zunino F: Change of the sequence specificity of daunorubicin-stimulated topoisomerase II DNA cleavage by epimerization of the amino group of the sugar moiety. Cancer Res 1995, 55:312-317.

12. Coon JS, Marcus E, Gupta-Burt S, Seelig S, Jacobson K, Chen S, Renta V, Fronda G, Preisler HD: Amplification and overexpression of topoisomerase Ilalpha predict response to anthracycline-based therapy in locally advanced breast cancer. Clinical cancer research: an official journal of the American Association for Cancer Research 2002, 8:1061-1067.

13. Press MF, Sauter G, Buyse M, Bernstein L, Guzman R, Santiago A, Villalobos IE, Eiermann W, Pienkowski T, Martin M, et al: Alteration of topoisomerase II-alpha gene in human breast cancer: association with responsiveness to anthracycline-based chemotherapy. Journal of clinical oncology: official journal of the American Society of Clinical Oncology 2011, 29:859-867.

14. Di Leo A, Gancberg D, Larsimont D, Tanner M, Jarvinen T, Rouas G, Dolci S, Leroy JY, Paesmans M, Isola J, Piccart MJ: HER-2 amplification and topoisomerase llalpha gene aberrations as predictive markers in node-positive breast cancer patients randomly treated either with an anthracycline-based therapy or with cyclophosphamide, methotrexate, and 5-fluorouracil. Clin Cancer Res 2002, 8:1107-1116.

15. Tanner M, Isola J, Wiklund T, Erikstein B, Kellokumpu-Lehtinen P, Malmstrom P, Wilking N, Nilsson J, Bergh J: Topoisomerase llalpha gene amplification predicts favorable treatment response to tailored and dose-escalated anthracycline-based adjuvant chemotherapy in HER-2/ neu-amplified breast cancer: Scandinavian Breast Group Trial 9401. J Clin Oncol 2006, 24:2428-2436.

16. O'Malley FP, Chia S, Tu D, Shepherd LE, Levine MN, Bramwell VH, Andrulis IL, Pritchard KI: Topoisomerase II alpha and responsiveness of breast cancer to adjuvant chemotherapy. J Natl Cancer Inst 2009, 101:644-650.

17. Pritchard Kl, Messersmith H, Elavathil L, Trudeau M, O'Malley F, Dhesy-Thind B: HER-2 and topoisomerase II as predictors of response to chemotherapy. Journal of clinical oncology: official journal of the American Society of Clinical Oncology 2008, 26:736-744.

18. Bartlett JM, Munro A, Cameron DA, Thomas J, Prescott R, Twelves CJ: Type 1 receptor tyrosine kinase profiles identify patients with enhanced benefit from anthracyclines in the BR9601 adjuvant breast cancer chemotherapy trial. Journal of clinical oncology: official journal of the American Society of Clinical Oncology 2008, 26:5027-5035.

19. Bartlett JM, Munro AF, Dunn JA, McConkey C, Jordan S, Twelves CJ, Cameron DA, Thomas J, Campbell FM, Rea DW, et al: Predictive markers of anthracycline benefit: a prospectively planned analysis of the UK National Epirubicin Adjuvant Trial (NEAT/BR9601). Lancet Oncol 2010, 11:266-274.

20. Di Leo A, Desmedt C, Bartlett JM, Piette F, Ejlertsen B, Pritchard Kl, Larsimont D, Poole C, Isola J, Earl H, et al: HER2 and TOP2A as predictive markers for anthracycline-containing chemotherapy regimens as adjuvant treatment of breast cancer: a meta-analysis of individual patient data. Lancet Oncol 2011, 12:1134-1142.

21. Oakman C, Moretti E, Sotiriou C, Viale G, Di Leo A: Re: Topoisomerase II alpha and responsiveness of breast cancer to adjuvant chemotherapy. J Natl Cancer Inst 2009, 101:1735-1736. author reply 1736-1737.

22. Razis E, Bobos M, Kotoula V, Eleftheraki AG, Kalofonos HP, Pavlakis K, Papakostas P, Aravantinos G, Rigakos G, Efstratiou I, et al: Evaluation of the association of PIK3CA mutations and PTEN loss with efficacy of trastuzumab therapy in metastatic breast cancer. Breast Cancer Res Treat 2011, 128:447-456.

23. Fountzilas G, Kourea HP, Bobos M, Televantou D, Kotoula V, Papadimitriou C, Papazisis KT, Timotheadou E, Efstratiou I, Koutras A, et al: Paclitaxel and bevacizumab as first line combined treatment in patients with metastatic breast cancer: the hellenic cooperative oncology group experience with biological marker evaluation. Anticancer Res 2011, 31:3007-3018

24. Christodoulou C, Kostopoulos I, Kalofonos HP, Lianos E, Bobos M, Briasoulis E, Gogas H, Razis E, Skarlos DV, Fountzilas G: Trastuzumab combined with pegylated liposomal doxorubicin in patients with metastatic breast cancer. phase II Study of the Hellenic Cooperative Oncology Group (HeCOG) with biomarker evaluation. Oncology 2009, 76:275-285.

25. Fountzilas G, Bobos M, Kalogera-Fountzila A, Xiros N, Murray S, Linardou $H$, Karayannopoulou G, Koutras AK, Bafaloukos D, Samantas E, et al: 
Gemcitabine combined with gefitinib in patients with inoperable or metastatic pancreatic cancer: a phase II Study of the Hellenic Cooperative Oncology Group with biomarker evaluation. Cancer Invest 2008, 26:784-793.

26. Hammond ME, Hayes DF, Dowsett M, Allred DC, Hagerty KL, Badve S, Fitzgibbons PL, Francis G, Goldstein NS, Hayes M, et al: American Society of Clinical Oncology/College Of American Pathologists guideline recommendations for immunohistochemical testing of estrogen and progesterone receptors in breast cancer. Journal of clinical oncology: official journal of the American Society of Clinical Oncology 2010, 28:2784-2795

27. Wolff AC, Hammond ME, Schwartz JN, Hagerty KL, Allred DC, Cote RJ, Dowsett M, Fitzgibbons PL, Hanna WM, Langer A, et al: American Society of Clinical Oncology/College of American Pathologists guideline recommendations for human epidermal growth factor receptor 2 testing in breast cancer. Journal of clinical oncology: official journal of the American Society of Clinical Oncology 2007, 25:118-145.

28. Cheang MC, Chia SK, Voduc D, Gao D, Leung S, Snider J, Watson M, Davies S, Bernard PS, Parker JS, et al: Ki67 index, HER2 status, and prognosis of patients with luminal B breast cancer. J Natl Cancer Inst 2009, 101:736-750

29. Gori S, Sidoni A, Colozza M, Ferri I, Mameli MG, Fenocchio D, Stocchi L, Foglietta J, Ludovini V, Minenza E, et al: EGFR, pMAPK, pAkt and PTEN status by immunohistochemistry: correlation with clinical outcome in HER2-positive metastatic breast cancer patients treated with trastuzumab. Annals of oncology: official journal of the European Society for Medical Oncology/ESMO 2009, 20:648-654.

30. Bhargava R, Lal P, Chen B: HER-2/neu and topoisomerase lla gene amplification and protein expression in invasive breast carcinomas: chromogenic in situ hybridization and immunohistochemical analyses. Am J Clin Pathol 2005, 123:889-895.

31. Fountzilas G, Ciuleanu E, Bobos M, Kalogera-Fountzila A, Eleftheraki AG, Karayannopoulou G, Zaramboukas T, Nikolaou A, Markou K, Resiga L, et al: Induction chemotherapy followed by concomitant radiotherapy and weekly cisplatin versus the same concomitant chemoradiotherapy in patients with nasopharyngeal carcinoma: a randomized phase II study conducted by the Hellenic Cooperative Oncology Group (HeCOG) with biomarker evaluation. Annals of oncology: official journal of the European Society for Medical Oncology/ESMO 2012, 23:427-435.

32. Knoop AS, Knudsen H, Balslev E, Rasmussen BB, Overgaard J, Nielsen KV, Schonau A, Gunnarsdottir K, Olsen KE, Mouridsen H, Ejlertsen B: retrospective analysis of topoisomerase lla amplifications and deletions as predictive markers in primary breast cancer patients randomly assigned to cyclophosphamide, methotrexate, and fluorouracil or cyclophosphamide, epirubicin, and fluorouracil: Danish Breast Cancer Cooperative Group. Journal of clinical oncology: official journal of the American Society of Clinical Oncology 2005, 23:7483-7490.

33. Bohmann $\mathrm{K}$, Hennig G, Rogel U, Poremba C, Mueller BM, Fritz P, Stoerkel S, Schaefer KL: RNA extraction from archival formalin-fixed paraffin-embedded tissue: a comparison of manual, semiautomated, and fully automated purification methods. Clin Chem 2009, 55:1719-1727.

34. McShane LM, Altman DG, Sauerbrei W, Taube SE, Gion M, Clark GM: Reporting recommendations for tumor marker prognostic studies (REMARK). J Natl Cancer Inst 2005, 97:1180-1184.

35. Zaczek A, Markiewicz A, Jaskiewicz J, Pienkowski T, Rhone P, Jassem J, Welnicka-Jaskiewicz M: Clinical evaluation of developed PCR-based method with hydrolysis probes for TOP2A copy number evaluation in breast cancer samples. Clin Biochem 2010, 43:891-898.

36. Lamy PJ, Fina F, Bascoul-Mollevi C, Laberenne AC, Martin PM, Ouafik L, Jacot W: Quantification and clinical relevance of gene amplification at chromosome 17q12-q21 in human epidermal growth factor receptor 2-amplified breast cancers. Breast cancer research: BCR 2011, 13:R15.

37. Slamon D, Eiermann W, Robert N, Pienkowski T, Martin M, Press $M$ Mackey J, Glaspy J, Chan A, Pawlicki M, et al: Adjuvant trastuzumab in HER2-positive breast cancer. N Engl J Med 2011, 365:1273-1283.

38. Callagy G, Pharoah P, Chin SF, Sangan T, Daigo Y, Jackson L, Caldas C: Identification and validation of prognostic markers in breast cancer with the complementary use of array-CGH and tissue microarrays. J Pathol 2005, 205:388-396.
39. Koren R, Rath-Wolfson L, Ram E, Itzhac OB, Schachter B, Klein B, Gal R, Dreznik Z: Prognostic value of Topoisomerase II in female breast cancer. Oncol Rep 2004, 12:915-919.

40. Lynch BJ, Guinee DG Jr, Holden JA: Human DNA topoisomerase II-alpha: a new marker of cell proliferation in invasive breast cancer. Hum Pathol 1997, 28:1 180-1188.

41. Turley H, Comley M, Houlbrook S, Nozaki N, Kikuchi A, Hickson ID, Gatter K, Harris AL: The distribution and expression of the two isoforms of DNA topoisomerase II in normal and neoplastic human tissues. $\mathrm{Br} J$ Cancer 1997, 75:1340-1346.

42. Kauraniemi P, Kallioniemi A: Activation of multiple cancer-associated genes at the ERBB2 amplicon in breast cancer. Endocr Relat Cancer 2006, 13:39-49.

43. Sircoulomb F, Bekhouche I, Finetti P, Adelaide J, Ben Hamida A, Bonansea J, Raynaud S, Innocenti C, Charafe-Jauffret E, Tarpin C, et al: Genome profiling of ERBB2-amplified breast cancers. BMC Cancer 2010, 10:539.

44. Slamon DJ, Press MF: Alterations in the TOP2A and HER2 genes: association with adjuvant anthracycline sensitivity in human breast cancers. J Natl Cancer Inst 2009, 101:615-618.

45. Nielsen KV, Ejlertsen B, Moller S, Jorgensen JT, Knoop A, Knudsen H, Mouridsen HT: The value of TOP2A gene copy number variation as a biomarker in breast cancer: Update of DBCG trial 89D. Acta Oncol 2008, 47:725-734.

doi:10.1186/1479-5876-10-212

Cite this article as: Fountzilas et al: Topoisomerase II alpha gene amplification is a favorable prognostic factor in patients with HER2-positive metastatic breast cancer treated with trastuzumab. Journal of Translational Medicine 2012 10:212

\section{Submit your next manuscript to BioMed Central and take full advantage of:}

- Convenient online submission

- Thorough peer review

- No space constraints or color figure charges

- Immediate publication on acceptance

- Inclusion in PubMed, CAS, Scopus and Google Scholar

- Research which is freely available for redistribution 